\title{
Statistical methodologies for wind resource analysis, case: Catatumbo region - Norte de Santander, Colombia
}

\author{
A.F. Lopez-Rodriguez ${ }^{1}$, J.C. Serrano-Rico ${ }^{2}$, E.G. Florez-Serrano ${ }^{3}$ \\ 1,2,3 Mechanical Engineering Program, Mechanical Engineering Research Group of the University of Pamplona (GIMUP), \\ Faculty of Engineering and Architecture, University of Pamplona - Colombia \\ Km 1 vía Bucaramanga Ciudad Universitaria, 543050 Pamplona (Colombia) \\ 1Phone/Fax number: +57 3142538401, e-mail: felipe1996.flr@gmail.com
}

\begin{abstract}
In this article, we analyze 4 probability distribution functions to characterize the wind resource at northeast zone of Colombia, based on data of taken from existing meteorological stations in three towns in the zone of Norte de Santander, Colombia. The data is sampled each 10 minutes, obtaining average values per hour every day, for each month of the year. The probability distributions studied are Weibull, Rayleigh, LogLogistics and Gamma. In the case of the Weibull distribution, 5 methods were used to estimate two principal parameters of the distribution; shape and scale. For other distributions only was used one. The distributions for each data set were determined, exposing the best fit for each zone according to the 3 performance indices considered (RMSE, $\chi \mathbf{2}$, R2). The main result obtained is the identification of the probability distribution that presents a better adjustment to the existing wind speed data in the zone where the meteorological stations are located. Specifically, it was identified that the probability distributions that best fit the data, for each month of the year, are Log-Logistics and Gamma. Further, the identification of the probability distribution that best fits to the wind speed data, allows to characterize with a greater degree of accuracy the wind potential of a zone.
\end{abstract}

Key words. Wind energy, probability distributions, wind speed, Colombia, wind resource.

\section{Introduction}

Given the serious effects that the environment suffers, there is a growing interest in venturing into the generation of electricity from renewable energy sources (RE), whose main virtue is the minimum or zero emission of carbon dioxide, ideal for achieving sustainable development in populations. Given the range of ER resources, the vast majority of countries focus on the development and optimization of solar and wind technology [1].

For the particular case of wind energy (WE), a measure of energy flow per unit area [2] and, according to [3], the interest in developing wind farms, focuses on methods to assess resource potential wind and how to increase the efficiency of wind turbines (and with it wind farms), so that this leads to greater profitability of the project, by reducing operation and capital costs, taking into account their generation capacity, annual growth of installed capacity, efficiency and long-term competitive cost [4], [5], [6], [7],
[8], [9]. Proof of this is how the WE covers $4 \%$ of the generation of electricity in the world, which for 2017 was $539 \mathrm{GW}$ [9] and an estimate of installed wind capacity close to $10,800,000 \mathrm{MW}$, which could cover all global electricity demand [10], ideal for large cities as for remote areas [11].

One of the main problems of the RE is the randomness of the resource [4], situation that leads to fluctuations in voltage and frequency, resulting in unbalanced and unstable systems [12]. Based on the research carried out by [13], wind energy forecasts are the most uncertain due to spatial and temporal variability [2] and predictability of the wind field. To address the randomness of the resource, research has been carried out on the analysis and application of probability distribution functions (PDF) that allow characterizing the wind resource [1], [3], [11], [14], [15], in order to study the feasibility and development of wind generation projects [3], [8], [9], [16]; and, therefore, to reduce the probability that the energy market is characterized by volatile and irregular prices between supply and demand [13].

Of the PDF, the Weibull distribution (of two parameters) has been the most used [1], [2], [4], [6], [7], [8], [10], [14], for the estimation (characterization) of the resource and the production of wind power, due to its simplicity and flexibility in the analysis of a wide range of data, however, according to the cited by [16], this distribution does not It is recommended for calm wind regimes (low wind speeds). These probability distribution studies in WE have been carried out in different countries in Asia, North America, Europe and North Africa, covering different time series, locations, temporal resolution, height at which the data is collected, among others [10]. However, probability distributions such as Rayleigh, log-normal, two-parameter gamma distribution, inverse Gaussian, 3-parameter generalized gamma distribution, kappa, generalized normal, Gumbel, three-log normal have been used parameters, beta distribution of 3 parameters, Pearson type III, log-Pearson type III, Burr, Erlang, Wakeby and the square root of the normal distribution, taking into account the cited by [9], [11], [16]. 
In the particular case of Colombia, there are few investigations and projects aimed at directing the country's electricity supply by ER sources, however, by $2017,80.3 \%$ of the energy generated, approximately $11725 \mathrm{MW}$, came from hydraulic generation [17]. In Colombia, 52\% of the territory is considered off-grid, represented in 2 million inhabitants, and to supply the demand for this type of areas, diesel-based systems and pass-through hydroelectric systems are used, expensive alternatives, with partial service and unreliable [18]. In Colombia, the wind farm located in the department of La Guajira stands out, which represents $6 \%$ of the $304.42 \mathrm{MW}$ in installed capacity of said department, for December 2017 [17].

In order to solve the intermittency of the resource in Colombia, hybrid systems that operate with storage systems (batteries that, if not given a correct post-use, can be a source of contamination, can continue to be designed and implemented) and diesel generation as a source of support, as developed by [18]. his is how interest arises because this research serves as a basis for future and eventual wind projects in the region and throughout Colombia, taking into account that it is the energy projects from ER that are being seen as an alternative to energize the areas without electric power [19].

For the present investigation, the focus of study is how to characterize wind speed from PDF. But, since not all distributions conform to the same data sets, the objective is, in addition, to give some guidelines to determine which distribution, of the ones discussed below, fits more to the set of analyzed data, taking into account the statistics descriptive calculated in the first instance.

\section{Interest Zone}

The area under study is the Catatumbo region of the department of Norte de Santander, Colombia. The interest of this area is because (in addition to the lack of electrical energy in the area) according to the Colombian Wind Atlas [20], developed by the Institute of Hydrology, Meteorology and Environmental Studies (IDEAM) and the Planning Unit Energy Miner (UPME), the average annual speed for the department of Norte de Santander (see Fig. 1), emphasizing the Catatumbo, ranges between 1 and $5 \mathrm{~m} / \mathrm{s}$, being the highest records for Colombia, exceeded only for the speeds registered in the Colombian Caribbean. The exact location of the weather stations you consider is shown in Fig. 1.

\section{Methodology}

The knowledge of the wind regime of a particular place is the essence in the determination of wind energy potential. The determination of this potential comprises two main aspects: the first is to measure the wind speed and a second aspect corresponds to the statistical analysis of these records. A more recently used technique is the use of artificial intelligence tools [21], [22]. In this investigation we will focus on the use of different continuous probability distributions used to assess wind power potential [23], [24].

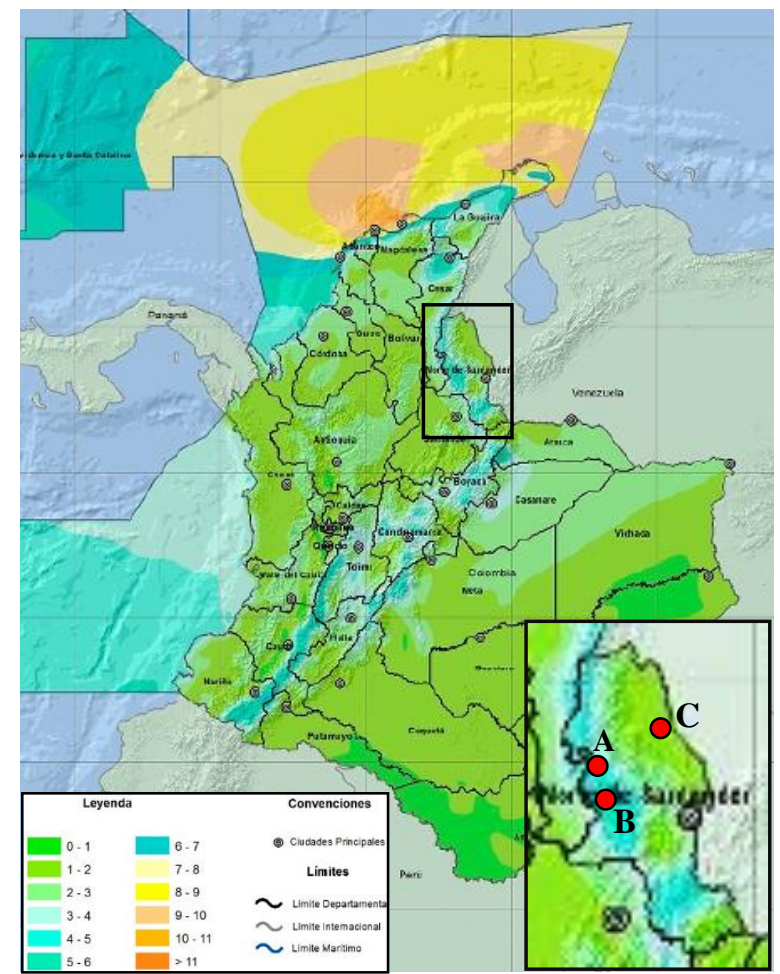

Fig. 1 Map of average annual wind speed at $10 \mathrm{~m}$ altitude of Colombia. Northern Sanatander Extension - Source: Taken and modified from [20]. Location of the meteorological stations considered for the study. a) Aguas Claras Airport; b) Abrego Administrative Center; c) Tibú.

\section{A. Probability distributions.}

The probability distributions widely for the analysis of wind speed data are the Weibull distribution and the Rayleigh distribution [25]. The Lindley distribution has also been used recently [26]. The Rayleigh distribution uses the average speed as a parameter, while the Weibull distribution uses two characteristic parameters. In this work, 4 probability density distributions are used to describe the distribution of wind speed for the different areas analyzed [11].

\section{1) Weibull distribution}

The Weibull distribution is a function characterized by two parameters and can represent a broad wind regime The probability density function of the Weibull distribution is given by the following expression [1], [2], [4], [7], [15]:

$$
f(v)=\frac{k}{c}\left(\frac{v}{c}\right)^{k-1} \exp \left[-\left(\frac{v}{c}\right)^{k}\right]
$$

The probability density function indicates the percentage of time by which the wind flows at a certain speed [14]. And the cumulative distribution function represented by [8]:

$$
F(v)=1-\exp \left[-\left(\frac{v}{c}\right)^{k}\right]
$$

Where $\mathrm{k}$ is the [dimensionless] form factor and $c(\geq 1)$ is the scale factor in $[\mathrm{m} / \mathrm{s}]$, therefore, calm conditions should be excluded from the analysis. These two parameters depend mainly on the average velocity $\bar{v}$ and $\sigma$, which is the standard deviation. Weibull parameters can be estimated using various statistical methods applied in 
different works that seek to determine wind potential [7], [27], [28], [29], [30], [31]:

\section{Maximum Probability Method (MPM)}

The MPM is the most used method to determine the parameters of the Weibull function. In this method numerical iterations are used to determine the shape parameter and the scale parameter once known the shape parameter can easily be determined by the following equations [16], [32]:

$$
\begin{gathered}
k=\left[\frac{\sum_{i=1}^{N} v_{i}^{k} \ln \left(v_{i}\right)}{\sum_{i=1}^{N} v_{i}^{k}}-\frac{\sum_{i=1}^{N} \ln \left(v_{i}\right)}{N}\right]^{-1} \\
c=\left(\frac{1}{N} \sum_{i=1}^{N} v_{i}^{k}\right)^{1 / k}
\end{gathered}
$$

Where $N$ represents the number of observations and $v_{i}$ the average wind speed recorded in the interval.

\section{Maximum Modified Probability Method (MMP)}

When wind speed records are in the frequency distribution format, the MMP method is used to determine Weibull parameters using the following expressions [16], [30]:

$$
\begin{gathered}
k=\left[\frac{\sum_{j=1}^{N} v_{j}^{k} \ln \left(v_{j}\right) P\left(v_{j}\right)}{\sum_{j=1}^{N} v_{j}^{k} P\left(v_{j}\right)}-\frac{\sum_{j=1}^{N} \ln \left(v_{j}\right) P\left(v_{j}\right)}{P(v \geq 0)}\right]^{-1} \\
c=\left(\frac{1}{P(v \geq 0)} \sum_{i-1}^{N} v_{i}^{k} P\left(v_{j}\right)\right)^{1 / k}
\end{gathered}
$$

Where $v_{j}$ is the central value of the wind speed interval $j, N$ is the number of classes, $P\left(v_{j}\right)$ is the frequency of class $j$, and $P(v \geq 0)$ is the probability that the wind speed $\geq 0$ As in the MMP method, Equation (5) must be solved by numerical methods and then calculate the scale parameter.

Moments Method (MM)

The moment method is a statistical estimation technique used to determine the parameters of any distribution. Weibull distribution parameters are determined by the following expressions [33], [34]:

$$
\begin{gathered}
\bar{v}=c \Gamma\left(1+\frac{1}{k}\right) \\
\sigma^{2}=c^{2}\left[\Gamma\left(1+\frac{2}{k}\right)-\Gamma^{2}\left(1+\frac{1}{k}\right)\right]
\end{gathered}
$$

Where $\Gamma$ is the Gamma function. Where $\bar{v}$ and $\sigma$ are calculated using the following expressions:

$$
\begin{gathered}
\bar{v}=\frac{1}{N} \sum_{i=1}^{N} v_{i} \\
\sigma=\left[\frac{1}{N-1} \sum_{i=1}^{N}\left(v_{i}-\bar{v}\right)^{2}\right]^{1 / 2}
\end{gathered}
$$

\section{Minimum Square Method or Graphic Method (MSM)}

Weibull parameters can be estimated graphically, using the cumulative distribution function. The data is interpolated by a straight line using the concept of least squares [35]. Equation (2) after some manipulations can be written as follows [34]:

$$
\ln [-\ln (1-F(v))]=k \ln v-k \ln c
$$

Equation (11) is in the form of a straight line $y=a x+b$. Then, if $\ln [-\ln (1-F(v))]$ is plotted against $\ln (v)$ it generates a straight line with slope $\mathrm{k}$ and with intercept with the y axis in $k \ln c$. Although the straight line can be graphically adjusted using a visual adjustment, making the adjustment by least squares regression achieves a better estimate of the distribution parameters.

\section{Empirical Method (EM)}

The EM is a method developed by [28], being a special case of the MM method and in which Equation (7) is proposed to determine the shape parameter [9]:

$$
k=\left(\frac{\sigma}{\bar{v}}\right)^{-1.086} \quad(1 \leq k \leq 10)
$$

Once $k$ is known, the scale parameter is determined by the following equation [4], [36]:

$$
c=\frac{\bar{v}}{\Gamma(1+1 / k)}
$$

\section{2) Rayleigh distribution}

The Rayleigh distribution is the simplest probability distribution used to represent the wind regime of a place. The Rayleigh distribution is a simplification of the Weibull distribution by approximating the scale factor $k=2$. The probability density function of the Rayleigh distribution $f(v)$ is given by [14]:

$$
f(v)=\frac{\pi}{2}\left(\frac{v}{\bar{v}^{2}}\right) \exp \left[-\frac{\pi}{4}\left(\frac{v}{\bar{v}}\right)^{2}\right]
$$

And the cumulative distribution function $F(v)$, as:

$$
F(v)=1-\exp \left[-\frac{\pi}{4}\left(\frac{v}{\bar{v}}\right)^{2}\right]
$$

\section{3) Log-Logistic Distribution}

The Log-logistics distribution recently used by [10] in WE analysis, which is frequently used in analyzes whose events suffer an increase rate at the beginning and subsequently decline (similar to what happens with the wind resource). It has a similar shape to the log-normal distribution, but it has lower kurtosis [37]. The PDF of the log-logistics distribution is given by:

$$
f(v)=\frac{(\beta / \alpha)(v / \alpha)^{\beta-1}}{\left(1+(v / \alpha)^{\beta}\right)^{2}}
$$

And the cumulative distribution function $F(v)$, as:

$$
F(v)=\frac{1}{1+(v / \alpha)^{-\beta}}
$$

The parameters can be determined using the mean and median value with the following expressions:

$$
\bar{v}=\frac{\alpha \pi / \beta}{\sin (\pi / \beta)} \quad \tilde{v}=\alpha
$$

\section{4) Gamma distribution}

The Gamma distribution is another of the PDF used in the evaluation of wind energy potential [24]. Like the Weibull distribution, the Gamma distribution has a scale parameter, $\lambda$, and a shape parameter, $r$. The PDF of the Gamma distribution is given by [11]: 


$$
f(v)=\frac{\lambda^{r} v^{r-1} \exp ^{-\lambda v}}{\Gamma(r)}, \quad v>0
$$

The parameters of scale and shape can be determined by using the mean and variance, with the following expressions:

$$
\bar{v}=\frac{r}{\lambda} \quad \sigma^{2}=\frac{r}{\lambda^{2}}
$$

\section{B. Evaluation Criteria of the distributions}

To evaluate the performance of the probability distributions, three indices serve as criteria to reflect the best adjustment of the distributions to the average wind speed records [14]. Chi-square $\chi^{2}$, square root of the mean square error RMSE (Root Mean Square Error) and the square multiple correlation coefficient $R^{2}$ (analysis of variance) [3], [7], [9], [31], [23]; which can be determined by the following expressions::

$$
\begin{gathered}
\chi^{2}=\frac{\sum_{i=1}^{N}\left(y_{i}-x_{i}\right)^{2}}{N-n} \\
R M S E=\left[\frac{1}{N} \sum_{i=1}^{N}\left(y_{i}-x_{i}\right)^{2}\right]^{1 / 2} \\
R^{2}=\frac{\sum_{i=1}^{N}\left(y_{i}-z\right)^{2}-\sum_{i=1}^{N}\left(x_{i}-y_{i}\right)^{2}}{\sum_{i=1}^{N}\left(y_{i}-z\right)^{2}}
\end{gathered}
$$

Where $y_{i}$ is the ith value of the probability of the recorded data, $\mathrm{Z}$ is the average value of the recorded data and $x_{i}$ is the ith value of the estimated data with the probability distribution $\mathrm{N}$ is the number of observations and $\mathrm{n}$ is the number of constants (one for the distribution of Rayleigh and two for the other distributions). The distribution that best fits the records corresponds to the highest value of $R^{2}$ and the lowest values of $\chi^{2}$ and RMSE.

\section{Analysis of results}

As stated in [3], [16], the analysis of the resource was carried out by time of day and by month for each year, according to the season in question.

\section{A) Collection of information}

The wind speed information analyzed in this work was obtained from the IDEAM database. Table 1 shows the names and codes of the stations, the height at which the

\begin{tabular}{|c|c|c|}
\hline Station & Location & $\begin{array}{c}\text { Period } \\
\text { analyzed }\end{array}$ \\
\hline Abrego & & 1983,1988, \\
\hline $\begin{array}{l}\text { Administrative Center } \\
\text { (AAC) - [16055040] }\end{array}$ & $8.087 ;-73.22$ & $\begin{array}{c}1989,1991- \\
1993\end{array}$ \\
\hline $\begin{array}{c}\text { Tibú }(\mathrm{TI})- \\
{[16035010]}\end{array}$ & $8.638 ;-72.73$ & $\begin{array}{c}1980-1983, \\
1992\end{array}$ \\
\hline $\begin{array}{l}\text { Aguas Claras Airport } \\
\text { (ACA) - [16055010] }\end{array}$ & $8.315 ;-73.36$ & 2015-2018 \\
\hline
\end{tabular}
data were collected, their location and the period analyzed.

Table 1 - Meteorological stations considered for the collection of wind data from the Catatumbo region, Norte de Santander, Colombia
As usual, in the databases of meteorological stations there are usually 'lost' data, values that were not recorded by the measuring instruments due to different factors. From these stations wind data were found for more years, but several with no data not only for some hours, but for several days, and even for up to 6 months in the same year; in this case, these records were omitted because they were going to reduce the reliability of the results.

With the aim of not leaving empty data spaces, a recovery of lost data was made with the help of the statistical software IBM SPSS Statistics with the multiple imputation procedure, since it is possible to complete the missing data taking into account the trend marked by the matrix of data, that is, taking into account the actual speeds recorded according to the day of the month and the hour.

Once the wind speeds were collected for each season, and classified by time, day, month and year, frequency tables were made, and then with this information determine the average speeds for different periods. To better appreciate the trend of the data, the average speed per hour and month was plotted for each period of each station (see Fig. 2).

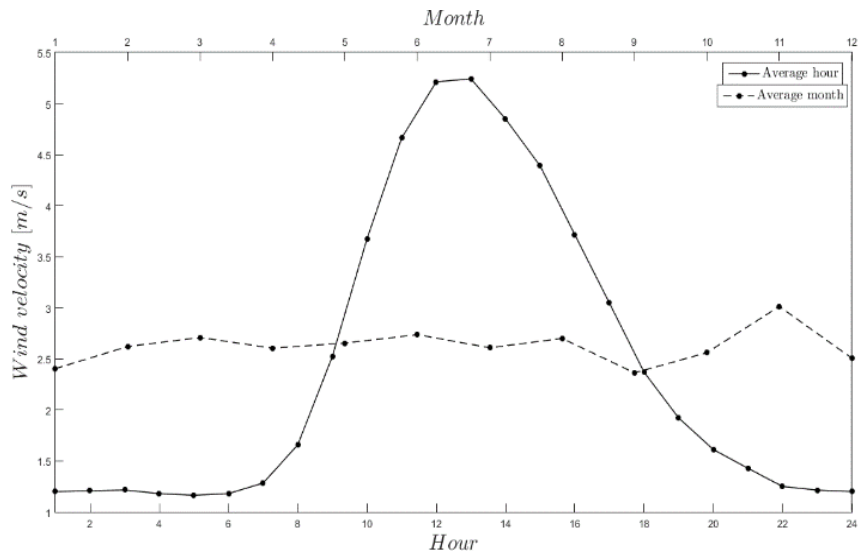

Fig. 2. Average speeds per hour and per month, Abrego Administrative Center, year 1993.

\section{B) Descriptive statistics}

Taking into account the importance of the calculation of the main descriptive statistics to estimate the probability distributions, and their respective parameters, the most relevant statistics and results of the information processing are recorded in Table 2. From the calculations recorded in this table it is noted that the higher speeds are recorded at the AAC station, followed by the TI station and finally the ACA station.

As the standard deviation is greater in the AAC station, the kurtosis for these data is between -0.16 and 0.6 , very acceptable values to establish that these data have a normal concentration, which translates into saying that very surely $95 \%$ of The data is within the limits of \pm 2 times the standard deviation. When considering the measure of distribution of asymmetry coefficient, it can be seen that the asymmetry in each year, of each station, is positive, which translates into saying that the vast majority of the data have lower average value.

C) Probability distribution functions (PDF's) 
In Fig. 3, you can see the distributions, described by the probability distribution functions, with the best fit for the data of each station. In the case of the Weibull distribution, the parameters of shape and scale were estimated with the 5 methods, so that at first glance you can have a notion of which of the methods offers a greater approximation to the wind speed records.

For each of the stations analyzed, the two distributions that best fit were the same for each data period. For the ACA station, the distributions with the best fit were Rayleigh and Weibull MM; for the AAC station, they were the LogLogistics and Gamma distributions; and as for the IT station, they were Weibull MMP and Rayleigh. In Fig. 3 the adjustment of these distributions for one year of each season is observed. In addition, graphically, it was possible to verify the asymmetry coefficients (positive for each case) obtained for each data set (see Table 2), since the graphs of all the distributions are skewed to the left. In ACA, the distributions yield probability values higher than the relative frequencies, however, each probability distribution is proportional to each frequency, with the advantage that it also contains all the data. For IT, the best adjustments were obtained, each estimated probability distribution greatly approximates the actual relative frequencies and the distributions cover all velocity data.

\section{D) Statistic analysis}

Once all distributions with the 3 performance indices were evaluated, it was found that the two distributions that best fit for each zone were the same for each analyzed period of the station in question. Therefore, for practicality, Table 3 shows the results obtained for one year of each of the 3 weather stations.

Taking into account the information contained in Table 3, it can be observed that, the distributions that best fit the data for AAC records is the Log-Logistic distribution and followed by the Gamma; for the ACA station the Rayleigh distribution fits better and then the Weibull MM; and in the case of IT, Rayleigh was first half, followed by the Weibull MMP. These yields were the same for the rest of the data periods in each station.

\section{Conclusions}

Taking into account the results obtained that are included in Table 2, and the estimation and evaluation of each distribution for each case, it was verified that when the asymmetry coefficient is $>0$ for the set of data in question, but also higher that the kurtosis, the best fit distributions are Log-Logistics and Gamma. If the data is analyzed carefully, this applies to cases in which the highest frequencies are for the lowest speeds, with a very small range of speeds prevailing with a tendency to $1 \mathrm{~m} / \mathrm{s}$. This clarifies the importance of calculating descriptive statistics first, since this can save time by discarding distributions that do not fit very well. Having this line of action, it can be seen that, at the outset, when the average and the median are very similar (disagree in less than one unit), the LogLogistic distribution cannot be estimated, so this could be considered as a convergence factor.

Although in some studies it has been emphasized not to consider the Weibull distribution for datasets with calm speeds, it is this research that has been concluded that, if the asymmetry and kurtosis are approximately equal, the distribution can cover all the data, although with $f(v)$ higher than the relative frequencies, but directly proportional to those frequencies. But when the kurtosis is much greater than the asymmetry, the adjustment of the Weibull and Rayleigh distribution is much more precise.

For future work, it is recommended to characterize the wind resource with other distributions, both for low speed records and for higher speeds. And for the particular case of Catatumbo, consider the data that is being recorded by the stations that began to register since the end of 2018. Although the wind speeds for the Catatumbo are not as high as in other parts of the world, if it should be considered for the energization of homes that are located in rural areas, distant from the network.

Table 2 Descriptive statistics for each of the stations selected according to each period analyzed

\begin{tabular}{ccccccccc}
\hline Station & Year & $\begin{array}{c}\text { Vel. } \\
\text { Maxim }\end{array}$ & $\begin{array}{c}\text { Mean } \\
(\mathrm{m} / \mathrm{s})\end{array}$ & $\begin{array}{c}\text { Median } \\
(\mathrm{m} / \mathrm{s})\end{array}$ & $\begin{array}{c}\text { Stand. } \\
\text { Deviation } \\
(\mathrm{m} / \mathrm{s})\end{array}$ & Variance & Asymmetry & Kurtosis \\
\hline Aguas Claras & 2015 & 4.5 & 1.42 & 1.3 & 0.64 & 0.41 & 1.28 & 1.49 \\
Airport & 2016 & 4.8 & 1.43 & 1.2 & 0.69 & 0.48 & 1.28 & 1.26 \\
& 2017 & 4.4 & 1.42 & 1.2 & 0.67 & 0.46 & 1.26 & 1.13 \\
\hline & 2018 & 4.4 & 1.40 & 1.2 & 0.69 & 0.47 & 1.30 & 1.25 \\
\hline Abrego & 1983 & 11.3 & 2.70 & 1.8 & 1.85 & 3.43 & 1.09 & 0.14 \\
Administrative & 1988 & 9.4 & 2.39 & 1.6 & 1.67 & 2.80 & 1.25 & 0.54 \\
Center & 1989 & 10.5 & 2.44 & 1.6 & 1.81 & 3.28 & 1.27 & 0.60 \\
& 1991 & 9.7 & 2.43 & 1.5 & 1.83 & 3.34 & 1.29 & 0.60 \\
& 1992 & 9.9 & 2.67 & 1.8 & 1.86 & 3.49 & 1.08 & 0.10 \\
& 1993 & 9.1 & 2.60 & 1.7 & 1.81 & 3.27 & 1.01 & -0.16 \\
\hline Tibú & 1980 & 8.3 & 1.87 & 1.6 & 0.86 & 0.75 & 1.84 & 5.71 \\
& 1981 & 8.8 & 1.87 & 1.6 & 0.85 & 0.72 & 1.70 & 5.46 \\
& 1982 & 9 & 1.70 & 1.6 & 0.78 & 0.60 & 1.13 & 3.74 \\
& 1983 & 9.9 & 1.39 & 1.3 & 0.94 & 0.89 & 1.35 & 5.19 \\
\hline
\end{tabular}



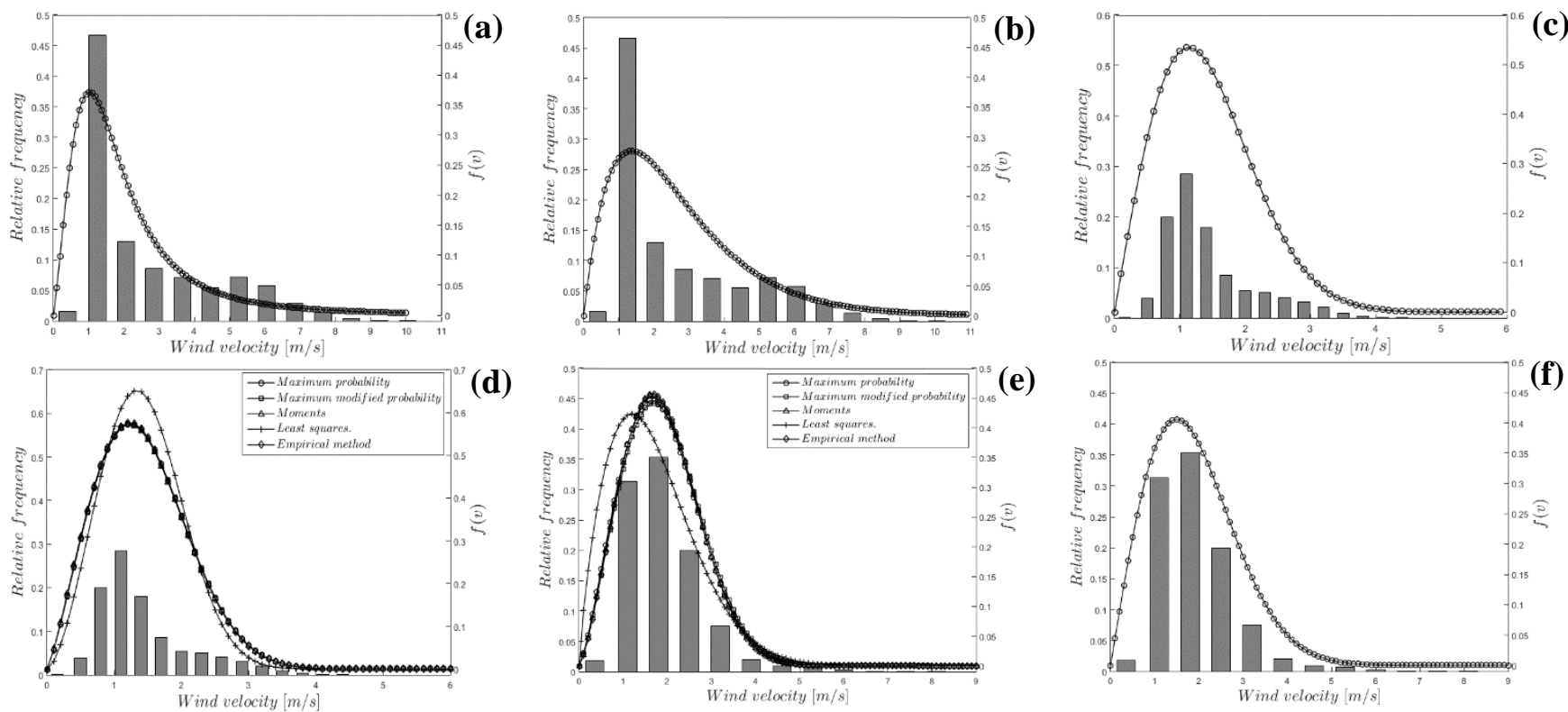

Fig. 3. Probably adjusted probability distributions for the analyzed data. For AAC (1992), the (a) Log-Logistics and (b) Gamma distributions; for ACA (2017) (c) Rayleigh and (d) Weibull MM; for TI (1981), the (e) Weibull MMP and (f) Rayleigh

Table 3 - Performance index for each distribution applied to the data of each station

\begin{tabular}{ccccc}
\hline Station/ & \multirow{2}{*}{ Dear } & Distribution & \multicolumn{3}{c}{ Performance index } \\
\cline { 3 - 5 } & Weibull PM & 0.00943 & 0.08936 & 0.9997789 \\
& Weibull MMP & 0.00944 & 0.08940 & 0.9997787 \\
& Weibull MM & 0.00945 & 0.08944 & 0.9997785 \\
AAC/ & Weibull GM & 0.00943 & 0.08937 & 0.9997789 \\
1992 & Weibull MSM & 0.00942 & 0.08929 & 0.9997793 \\
& Rayleigh & 0.01094 & 0.10051 & 0.9997203 \\
& Gamma & 0.00809 & 0.08278 & 0.9998103 \\
& Log-Logistic & 0.00602 & 0.07139 & 0.9998588 \\
\hline \multirow{4}{*}{ Weibull PM } & 0.05120 & 0.21066 & 0.993464 \\
& Weibull MMP & 0.05119 & 0.21064 & 0.993465 \\
ACC/ & Weibull MM & 0.05104 & 0.21032 & 0.993485 \\
& Weibull MSM & 0.06117 & 0.23128 & 0.992121 \\
& Weibull EM & 0.05151 & 0.21130 & 0.993424 \\
& Rayleigh & 0.04310 & 0.20057 & 0.994074 \\
& Gamma & 0.05505 & 0.21844 & 0.992972 \\
& Log-Logistic & 0.05930 & 0.22670 & 0.992430 \\
\hline \multirow{4}{*}{ TI/ } & Weibull PM & 0.003533 & 0.05426 & 0.998752 \\
& Weibull MMP & 0.003572 & 0.05456 & 0.999873 \\
& Weibull MM & 0.00336 & 0.05514 & 0.999871 \\
& Weibull MSM & 0.00633 & 0.07263 & 0.999776 \\
& Weibull EM & 0.00369 & 0.05550 & 0.999869 \\
& Rayleigh & 0.00323 & 0.05445 & 0.998743 \\
& Gamma & 0.00397 & 0.05755 & 0.999859 \\
& Log-Logistic & 0.00538 & 0.06696 & 0.999809 \\
\hline & & & &
\end{tabular}

\section{Acknowledgments}

The authors gratefully acknowledge the financial support provided by the Ministry of National Education-MEN, the Ministry of Trade, Industry and Tourism-MinCIT, the Colombian Institute of Educational Credit and Technical Studies Abroad-ICETEX and the Administrative Department of Science, Technology and InnovationCOLCIENCIAS through the Scientific Colombia Program.

\section{References}

[1] M. Aksas and A. Gama, "Assessment of wind and solar energy resources in Batna, Algeria," Energy Procedia, vol. 6, pp. 459-466, 2011.

[2] N. Nawri et al., "The wind energy potential of Iceland," Renew. Energy, vol. 69, pp. 290-299, 2014.

[3] M. Nedaei, E. Assareh, and P. R. Walsh, "A comprehensive evaluation of the wind resource characteristics to investigate the short term penetration of regional wind power based on different probability statistical methods," vol. 128, no. 2018, pp. 362-374, 2020.

[4] N. Aghbalou, A. Charki, S. R. Elazzouzi, and K. Reklaoui, "A probabilistic assessment approach for wind turbine-site matching," Electr. Power Energy Syst., vol. 103, no. April, pp. 497-510, 2018.

[5] M. Eichhorn, F. Masurowski, R. Becker, and D. Thr, "Wind energy expansion scenarios e A spatial sustainability assessment," Energy, vol. 180, no. 2019, pp. 367-375, 2019.

[6] W. Promsen, S. Janjai, and T. Tantalechon, "An Analysis of Wind Energy Potential of Kampot Province, Southern Cambodia," Energy Procedia, vol. 52, pp. 633-641, 2014.

[7] A. K. Azad, M. G. Rasul, R. Islam, and I. R. Shishir "Analysis of wind energy prospect for power generation by three Weibull distribution methods," Energy Procedia, vol. 75, no. 2015, pp. 722-727, 2015.

[8] M. R. Islam, R. Saidur, and N. A. Rahim, "Assessment of wind energy potentiality at Kudat and Labuan, Malaysia using Weibull distribution function," Energy, vol. 36, pp. 958-992, 2011.

[9] M. K. Saeed, A. Salam, A. Ur, and M. A. Saeed, "Comparison of six di ff erent methods of Weibull distribution for wind power assessment : A case study for a site in the Northern region of Pakistan," Sustain. Energy Technol. Assessments, vol. 36, no. August, pp. $1-11,2019$.

[10] C. Jung and D. Schindler, "Wind speed distribution selection - A review of recent development and progress," Renew. Sustain. Energy Rev., vol. 114, no. June, pp. 1-13, 2019. 
[11] O. Alavi, K. Mohammadi, and A. Mostafaeipour, "Evaluating the suitability of wind speed probability distribution models: A case of study of east and southeast parts of Iran," Energy Convers. Manag., vol. 119, pp. 101-108, 2016.

[12] P. Das, J. Mathur, R. Bhakar, and A. Kanudia, "Implications of short-term renewable energy resource intermittency in long- term power system planning," Energy Strateg. Rev., vol. 22, no. July, pp. 1-15, 2018.

[13] I. González-Aparicio and A. Zucker, "Impact of wind power uncertainty forecasting on the market integration of wind energy in Spain q," Appl. Energy, vol. 159, no. 2015, pp. 334-349, 2015.

[14] H. Bidaoui, I. El Abbassi, A. El Bouardi, and A. Darcherif, "Wind Speed Data Analysis Using Weibull and Rayleigh Distribution Functions, Case Study: Five Cities Northern Morocco," Procedia Manuf., vol. 32, no. 2019, pp. 786-793, 2019.

[15] B. Figueroa-espinoza et al., "On the wind power potential in the northwest of the Yucatan Peninsula in Mexico," Atmósfera, vol. 27, no. 1, pp. 77-89, 2014.

[16] V. Katinas, G. Gecevicius, and M. Marciukaitis, "An investigation of wind power density distribution at location with low and high wind speeds using statistical model," Appl. Energy, vol. 218, no. February, pp. 442451, 2018.

[17] G. Carvajal-romo, M. Valderrama-mendoza, D. Rodríguez-urrego, and L. Rodríguez-urrego, "Assessment of solar and wind energy potential in $\mathrm{La}$ Guajira, Colombia: Current status, and future prospects," Sustain. Energy Technol. Assessments, vol. 36, no. August, pp. 1-15, 2019.

[18] J. P. Viteri, F. Henao, J. Cherni, and I. Dyner, "Optimizing the insertion of renewable energy in the offgrid regions of Colombia," J. Clean. Prod., vol. 235, pp. 535-548, 2019.

[19] Á. Pinilla Sepúlveda, "Soluciones energéticas para zonas rurales (¿En el posconflicto?)," Reista Ing., vol. 44, pp. 36-39, 2016.

[20] J. F. Ruíz Murcia, J. Serna Cuenca, and H. J. Zapata Lesmes, "Atlas de Viento de Colombia," IDEAM; UPME. González, Olga Cecilia; Correa Amaya, Ruth Leonor; Ramírez Acosta, Eduardo Emilio; Bulla Portuguez, Paola Andrea, Bogotá D.C., p. 158, 2017.

[21] "Forecasting meteorology models implemented by the feed-forward architecture of neural networks | Request PDF." [Online]. Available: https://www.researchgate.net/publication/256095340_F orecasting_meteorology_models_implemented_by_the_ feed-forward_architecture_of_neural_networks. [Accessed: 25-Oct-2019].

[22] D. A. Fadare, "The application of artificial neural networks to mapping of wind speed profile for energy application in Nigeria," Appl. Energy, vol. 87, no. 3, pp. 934-942, 2010.

[23] T. B. M. J. Ouarda, C. Charron, and F. Chebana, "Review of criteria for the selection of probability distributions for wind speed data and introduction of the moment and L-moment ratio diagram methods, with a case study," Energy Convers. Manag., vol. 124, pp. $247-$ 265, 2016.

[24] J. A. Carta, P. Ramírez, and S. Velázquez, "A review of wind speed probability distributions used in wind energy analysis. Case studies in the Canary Islands," Renewable and Sustainable Energy Reviews, vol. 13, no. 5. pp. 933955, Jun-2009.

[25] J. F. Manwell, J. G. McGowan, and A. L. Rogers, Wind energy explained: theory, design and application, Second Edi. Great Bretain: U.K., Chichester, 2009.

[26] Y. Mert, I. Usta, I. Arik, and I. Yenilmez, "Wind speed analysis using the Extended Generalized Lindley Distribution," Renew. Energy, vol. 118, pp. 1024-1030, 2018.

[27] J. Serrano Rico, "Comparación de métodos para determinar los parámetros de Weibull para la generación de energía eólica," Sci. Tech., vol. 18, no. 2, pp. 315320, 2013.

[28] C. G. Justus, W. R. Hargraves, A. Mikhail, and D. Graber, "Methods for estimating wind speed frequency distributions.," J. APPL. METEOROL., vol. 17, no. 3, Mar. 1978, pp. 350-353, 1978.

[29] R. D. Christofferson and D. A. Gillette, "A Simple Estimator of the Shape Factor of the Two-Parameter Weibull Distribution," J. Clim. Appl. Meteorol., vol. 26, no. 2, pp. 323-325, Feb. 1987.

[30] J. V. Seguro and T. W. Lambert, "Modern estimation of the parameters of the Weibull wind speed distribution for wind energy analysis," J. Wind Eng. Ind. Aerodyn., vol. 85, no. 1, pp. 75-84, Mar. 2000.

[31] C. F. De Andrade, H. Falcão, M. Neto, P. Alexandre, C. Rocha, and M. Eugênia, "An efficiency comparison of numerical methods for determining Weibull parameters for wind energy applications: A new approach applied to the northeast region of Brazil," Energy Convers. Manag., vol. 86, pp. 801-808, 2014.

[32] T. J. Chang, Y. T. Wu, H. Y. Hsu, C. M. Liao, and C. R. $\mathrm{Chu}$, "Assessment of wind characteristics and wind turbine characteristics in Taiwan," Renew. Energy, vol. 28, no. 6, pp. 851-871, 2003.

[33] I. Usta, "An innovative estimation method regarding Weibull parameters for wind energy applications," Energy, vol. 106, pp. 301-314, 2016.

[34] C. Ozay and M. S. Celiktas, "Statistical analysis of wind speed using two-parameter Weibull distribution in Alaçatı region," Energy Convers. Manag., vol. 121, pp. 49-54, 2016.

[35] G. K. Gugliani, A. Sarkar, C. Ley, and S. Mandal, "New methods to assess wind resources in terms of wind speed, load, power and direction," Renew. Energy, vol. 129, pp. 168-182, Dec. 2018.

[36] S. Ali, S. Lee, and C. Jang, "Statistical analysis of wind characteristics using Weibull and Rayleigh distributions in Deokjeok-do Island e Incheon, South Korea," Renew. Energy, vol. 123, pp. 652-663, 2018.

[37] J. Wu, J. Wang, and D. Chi, "Wind energy potential assessment for the site of Inner Mongolia in China," Renewable and Sustainable Energy Reviews, vol. 21. Elsevier Ltd, pp. 215-228, 2013. 